\title{
Recognition of supraduodenal artery from hepatic artery is essential to avoid untoward complications at HAIC: two cases
}

\author{
Tzu-Hao Ou, Ding-Kwo Wu, Paul Ming-Chen Shih, Min-Fang Chao
}

Department of Medical Imaging, Kaohsiung Medical University Chung Ho Memorial Hospital, Kaohsiung, Taiwan

Correspondence to Dr Tzu-Hao Ou, omonregar@gmail.com

Accepted 7 April 2018

\section{DESCRIPTION}

Supraduodenal artery (SDA) supplies the proximal duodenum, which originates most commonly from gastroduodenal artery (GDA), followed by common and proper hepatic artery. ${ }^{12}$ Origination from left hepatic artery (LHA) is relatively rare and only few articles have addressed this anatomic variation. ${ }^{3}$ Recognition of such an aberrant artery and proper coiling before liver-directed therapy are essential to prevent non-target organ injury. Herein, we report two rare cases of SDA that originated from the LHA.

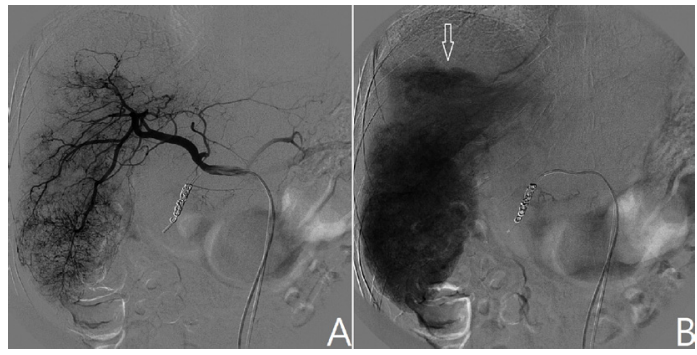

Figure 1 Common hepatic artery arteriography showing massive type hepatocellular carcinoma at right lobe of liver $(A)$ and right portal vein thrombosis on the delayed images (B). A previous hepatic arterial infusion chemotherapy catheter placed in GDA was depicted on both images. He suffered from intense epigastric upset during the first cycle of intrahepatic arterial infusion with 5-Fluorouracil $50 \mathrm{mg}$ and Cisplatin $10 \mathrm{mg}$ daily for 5 consecutive days in a week and sustained massive upper gastrointestinal bleeding at the second day of second cycle infusion.

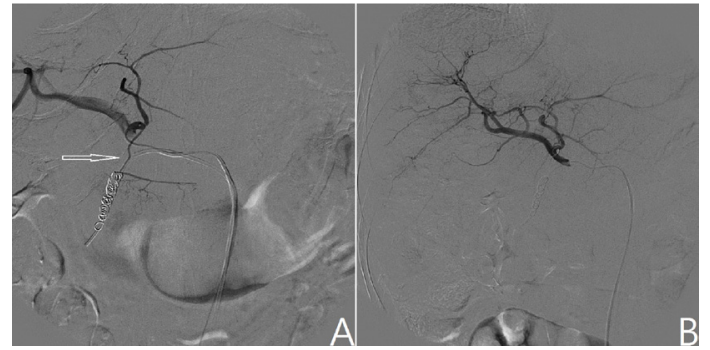

To cite: OU T-H, Wu D-K, Shih PM-C, et al. BMJ Case Rep Published Online First: [please include Day Month Year]. doi:10.1136/bcr-2017223627
Figure 2 LHA arteriography showed that the SDA originated from the LHA (A), and we successfully embolised the SDA with a 3-2 mm Vortx minicoil (Boston Scientific) (B) and proceeded with TACE. LHA, left hepatic artery; SDA, supraduodenal artery.

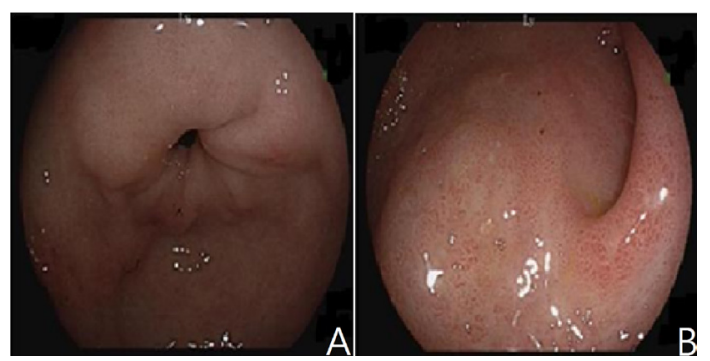

Figure 3 This 59-year-old man with recurrent HCCs in both hepatic lobes had intractable epigastralgia after 1st temporary HAIC (Cisplatin $10 \mathrm{mg}$, Mitomycin-C $2 \mathrm{mg}$ and 5-Fluorouracil $100 \mathrm{mg}$ daily for 1 week). Panendoscope revealed haemorrhagic duodenitis and shallow ulcers from gastric antrum to 1 st portion of duodenum $(A, B)$.

\section{Case 1}

A 56-year-old man had a massive type hepatocellular carcinoma (HCC) in right hepatic lobe with right portal vein tumour thrombosis (figure 1). He had one episode of massive upper gastrointestinal bleeding at 2 nd hepatic arterial infusion chemotherapy (HAIC) and panendoscope revealed haemorrhagic duodenitis with duodenal bulb ulcer. In our hospital, a SDA that originated from the LHA was found at angiography, which was successfully embolised with a minicoil (figure 2) with the assistance of a 'Swan-neck configuration' microcatheter (Maestro, Merit)

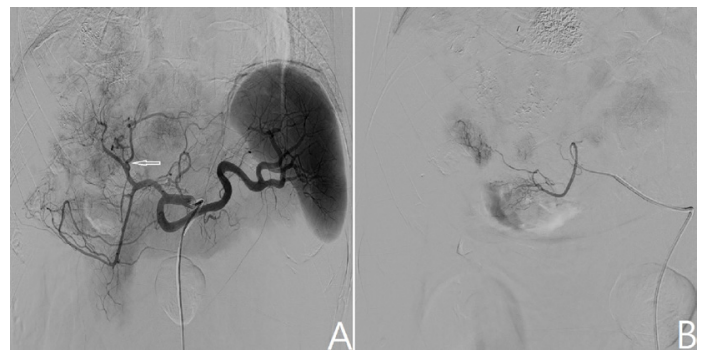

Figure 4 Celiac artery arteriography showed multinodular type HCC in bilateral lobes of liver. A SDA that originated from the LHA was identified (Arrow, A). SDA arteriography revealed staining of proximal duodenum and tumours in bilateral hepatic lobes (B). LHA, left hepatic artery; SDA, supraduodenal artery. 


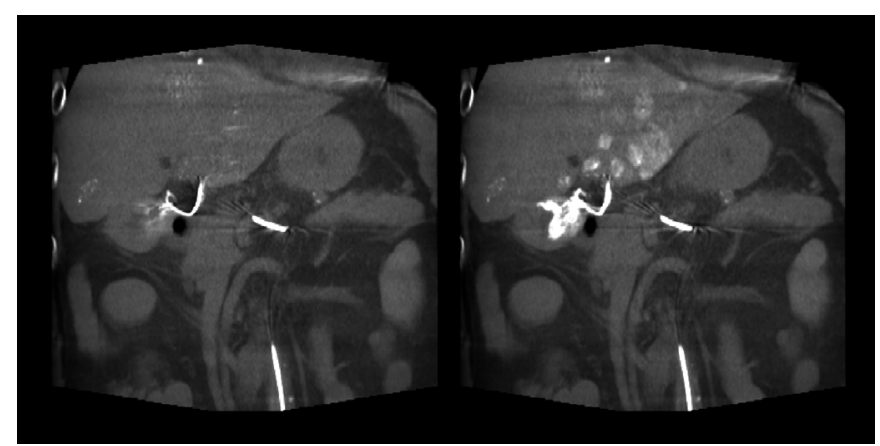

Figure 5 Angio-CT of SDA showed proximal duodenal wall enhancement and enhanced nodules in bilateral lobes of liver, which confirmed this artery to be the supraduodenal artery and parasitic vessel supplying the HCC as well. SDA, supraduodenal artery.

and proceeded with transarterial chemoembolization (TACE) and subsequent HAIC without identical complication.

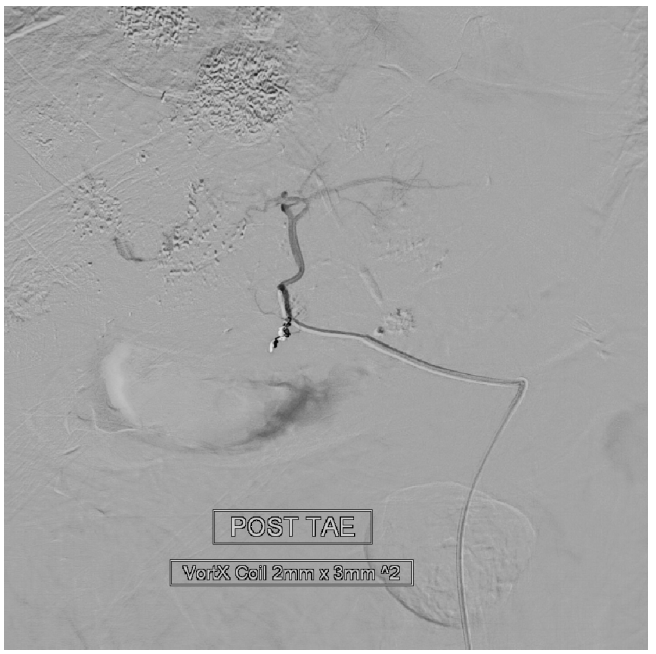

Figure 6 We successfully embolised the SDA with two 2-3 mm Vortx minicoils. SDA, supraduodenal artery.

\section{Learning points}

- Recognition of supraduodenal artery (SDA) variation to avoid iatrogenic duodenitis and peptic ulcer in liver-directed therapy.

- SDA may act as a parasitic vessel supplying the liver tumour.

- Cone-Beam CT/Angio-CT can be very effective to confirm origin of SDA from left hepatic artery.

\section{Case 2}

A 59-year-old man with recurrent HCCs in both hepatic lobes underwent 6th TACE followed by temporary HAIC. $\mathrm{He}$ had intractable epigastralgia after HAIC. Panendoscope revealed haemorrhagic duodenitis and shallow ulcers from gastric antrum to 1 st portion of duodenum (figure 3). A SDA, that originated from the LHA, was identified (figure 4) and proven to supply the proximal duodenum by cone-beam CT (figure 5). It also acted as a parasitic vessel supplying the right lobe tumour. We successfully embolised the SDA with minicoils (figure 6) to prepare for next HAIC/TACE if clinically indicated.

Contributors T-HO: main author. D-KW: main director. PM-CS: second director. M-FC: surgery assistant.

Funding The authors have not declared a specific grant for this research from any funding agency in the public, commercial or not-for-profit sectors.

Competing interests None declared.

Patient consent Next of kin consent obtained.

Provenance and peer review Not commissioned; externally peer reviewed. (c) BMJ Publishing Group Ltd (unless otherwise stated in the text of the article) 2018. All rights reserved. No commercial use is permitted unless otherwise expressly granted.

\section{REFERENCES}

1 Lee AJ, Gomes AS, Liu DM, et al. The road less traveled: importance of the lesser branches of the celiac axis in liver embolotherapy. Radiographics 2012;32:1121-32

2 Bianchi HF, Albanèse EF. The supraduodenal artery. Surg Radiol Anat 1989;11:37-40

3 Kapoor BS, Berscheid B, Saddekni S. Supraduodenal branch of the left hepatic artery: a rare cause of bleeding duodenal ulcer. Cardiovasc Intervent Radiol 2009;32:789-91

Copyright 2018 BMJ Publishing Group. All rights reserved. For permission to reuse any of this content visit http://group.bmj.com/group/rights-licensing/permissions.

BMJ Case Report Fellows may re-use this article for personal use and teaching without any further permission.

Become a Fellow of BMJ Case Reports today and you can:

- Submit as many cases as you like

- Enjoy fast sympathetic peer review and rapid publication of accepted articles

- Access all the published articles

- Re-use any of the published material for personal use and teaching without further permission

For information on Institutional Fellowships contact consortiasales@bmjgroup.com

Visit casereports.bmj.com for more articles like this and to become a Fellow 